\title{
Does Moral Foundations Theory Reveal that Teens Aren't Entirely Split on P.C. Culture in Higher Education?
}

Joaquín M. Lara Midkiff
Yale University, New Haven, CT

What follows is a revision of earlier work based on research carried out as a student at West Salem High School, Salem, OR (Spring 2019).

\begin{abstract}
The rise of Moral Foundations Theory (MFT) as a psychometric tool aimed at formalizing the study of political and moral psychology has led to many empirical studies and surveys over the last fifteen years. This present study documents the relationship between self-reported political identities, Moral Foundations Questionnaire (MFQ)-determined political ideology, and a novel attitude assessment concerning political correctness (PC) in academia among randomly sampled high schoolers at a demographically representative and statistically unremarkable high school in the American Pacific Northwest. Contrary to the emerging consensus in this recent field of MFT psychology, evidence here suggests that teenagers of varying political allegiances may be in general agreement when it concerns a political issue that has predominated headlines in the United States: PC culture (and censorship broadly) found in American universities. Though largely a vindication of antecedent MFT surveys, does this unanticipated alignment indicate a possible acquiescence in the zeitgeist of an up-and-coming generation?
\end{abstract}

\section{Introduction}

The MFT approach in social psychology has come into its own with an unprecedented string of studies, surveying thousands of people around the globe, that confirm many of its central predictions (e.g. differential moralization across cultures, correlation between moral axis proclivities and political ideology, etc.) such that greater confidence may be placed in its explanatory and psychometric value (Graham et al. 2012). At its core, MF theory introduces five experimentally substantiated categories/axes that encapsulate moral consideration and decision making (i.e. Care/Harm, Fairness/ Reciprocity, Loyalty/Ingroup, Authority/ Respect and Sanctity/Purity). These are to be considered innate, "moral foundations" conferred on us by our evolutionary heritage; they are the moral muscles we flex in every ethical consideration (conscious or otherwise) that we encounter (Haidt 2012). And these very five axes seem to correlate, to incredible success and predictive value, with political affiliations and ideological commitments that, in the United States, we recognize as the Left (i.e. liberalism, progressivism, the Democratic party) and the Right (i.e. conservatism, the Republican party). More recently, Gladden and Cleator (2018) have ventured a sixth foundation (Liberty/Oppression) in accordance with predictions made by slow life history (LH) theory and in response to the lack of 
representation of non-dichotomous political views (e.g. libertarianism).

The informative potential of the MFT methodology has been exercised, in the last few years alone, in areas as diverse as business ethics, cooperation psychology, the psychology of sex, and beyond (Egorov et al 2019; Curry 2019; Harper 2016). Germane here is the way in which teens think about a term that does not appear to be losing significance since entering circulation thirty years ago-political correctness (Bernstein 1990). And though it has been noted that politically correct speech and litigation is not a phenomenon endemic to the U.S. and the West (Cohen 2012), the ways in which certain facets of the phenomenon interface with American life (e.g. free speech on campus, education policy broadly) is of great interest to many in this country. From "P.C. Reviews" to public protests over invited guest speakers and lecturers (Ravitch 2003; Chemerinsky \& Gillman 2017), Western society is seeing this phenomenon's most recent permutation. Important to understanding the psychology of such a phenomenon, yet largely underexplored, is empirically evaluating the attitudes harbored by high schoolers; this is only natural given that they are the future college students and soon-to-be participants in this particular unfolding social drama.

Political correctness can be described as a tension between activist tendencies (specifically, those intolerant of speech or averse to actions that are deemed offensive, inappropriate, or insensitive) and tendencies that either prioritize the conservation of the status quo, negate and/or are indifferent to 'politically correct' efforts by the former. Framed in this manner, political correctness, as a psychological phenomenon, is deeply compatible with MFT analysis. Given that the Left is associated more with a higher concern for the Care/Harm and Fairness/Reciprocity foundations, the activist tendency is exasperated; therefore, PC culture anywhere (but specifically in academia) will be more easily accepted and fostered by liberals. By way of contrast, conservatives (who are on average better rounded among the axes) would likely find such political inclinations less appealing (Graham, Haidt, \& Nosek 2009).

\section{Method}

Participants. Student participants totaled 114 (63\% female, 37\% male; total std. pop. $=1,500)$. Studies were distributed to classes whose teachers permitted my interruption and responses were completed and submitted within a seven day period by whomever volunteered their time. Participants were asked to self-identify politically on a 6-point scale: Liberal, Slightly Liberal, Moderate, Slightly Conservative and Conservative; participants could also opt for a $7^{\text {th }}$-point alternative, Don't Know/Undecided. (This was done in an attempt to accommodate high schoolers who had yet to solidify a political commitment.) Additionally, gender, age, grade level (11-12) were recorded at the start of the survey. All students were required to complete an Informed Consent Form (IFC), with minors requiring parent permission. Each of the three sections of the study were reviewed by an independent Institutional Review Board (IRB) consisting of high school faculty with subject matter expertise. The participant pool was generally reflective of the larger school demography.

\section{Materials}

MFT Questionnaire. Participants were given the standard Graham et al. (2009) Moral Foundations Questionnaire (MFQ) (see Appendix A). In accordance with 
former literature, the Questionnaire totaled thirty-two questions divided among two parts (both Part A and Part B had sixteen questions). Part A assessed the participant's invocation of given parameters in their moral decision making. (The parameter in question six, 'Whether or not someone was good at math,' was used as an obvious control.) By contrast, Part B evaluated the extent to which a participant agreed or disagreed with a provided moral statement. (Here, again, question six was used to control for obvious flipency, with the uncontroversial and uninformative moral conjecture that 'It is better to do good than to do bad.')

Attitudes Survey. Given that few psychometric tools exist that satisfyingly assess the attitudes of high schoolers regarding the role of PC culture in institutions of higher education, I was forced to create my own. My assessment was framed in language similar (e.g. comparable in tone, length, general format) to the MFQ which participants would have completed prior to the novel Student Political Correctness Attitude Assessment (SPCAA). The SPCAA operates under the premise that there are two overarching tendencies, in part addressed earlier, that lend themselves well to the respective divergent dichotomous political persuasions. I identify these tendencies as the emotive (e.g. liberal, activist) and the affectless (e.g. conservative). It is critical to underscore that in no way is a value judgement being made here; the aforementioned dichotomy is agnostic on the question of whether liberals are more emotional than conservatives, or conservatives more placid than liberals. However, with respect to PC culture in universities, they serve as appropriate qualifiers for the liberal and conservative concept categories, respectively.
Overall the SPCAA, as delivered to participants, comprised ten questions. Half were attributable to activist (e.g. liberal) positions, while half belonged in the conservative category. An equitable split between moral statements (e.g. 'Universities and their faculty should follow the truth, no matter where it leads') and short historical events and/or hypotheticals (e.g. 'Universities should revoke the tenures of professors who, in any capacity, directly or indirectly, discuss differences among races and/or the sexes in a classroom or laboratory setting') were presented; respondents ranked their Strong Disagreement (0) to Strong Agreement (5) - in a style similar to the MFQ (refer to Appendix $\mathbf{B}$ as well as Figure 2 for full SPCAA; Appendix $\mathbf{C}$ for scoring method).

Procedure. Both parts of the study were implemented online through a hyperlink sent to students via participant's district e-mail addresses. The MFQ and SPCAA were made available in GoogleForm for a duration of one week, January 21st-28th. The average time it took for participants to become respondents was $\approx 14.5$ minutes.

\section{Results}

All participants became respondents; none had their responses invalidated either by failing the control questions or being unable to complete the survey in the time allotted.

Self-Reported Political Identity. Of the 114 respondents, 18 described themselves as Liberal/Left (15.8\%); 42 identified as Slightly Liberal/Left (36.8\%); 12 called themselves Moderate (10.5\%); 12 said they were Slightly Conservative/Right (10.5\%); and another 12 said they were Conservative/Right (10.5\%). Lastly, 18 participants selected Don't Know/Undecided 
$(15.8 \%)$. In aggregate, the study was divided among those that self-identify as Liberal (52.6\%), moderate/centrist (10.5\%), and Conservative (21\%). Resultantly, given a high volume of Undecideds, the MFQ is of heightened import.

Moral Foundations Questionnaire. These data result in a clarification of some of the ambiguity found in the preceding section. Principally, all undecideds fell under the conservtive umbrella (e.g. Slightly conservative, Conservative). Undecided/s $(0 \%)$ were categorically eliminated in Part II. Ultimately, Part II presented us with a significantly better ideological representation with a new, larger Conservative aggregate $(43 \%, n=49)$. Qualified Moderates decreased (25\%) from 12 to 8 students. Figure 1 represents this change between Part I and Part II (students, $\mathrm{n}=114)$.

Student P.C. Attitude Assessment. Relatively few students $(24 \%, \mathrm{n}=27)$ scored a mean favoring the emotive $(\mu>0)$; this is to say, that only a quarter of respondents qualified for the projected, so-called Liberal position largely associated with teens (Parker, Graf, Igielnik 2019). However, expectedly, the overwhelming majority of these minority respondents were MFQ Liberals (81\%, $\mathrm{n}=22$; Conservatives: $15 \%$, $\mathrm{n}=4$; Moderates: 4\%, $\mathrm{n}=1$ ). Outstandingly, Liberals and Conservatives appear to be in consensus on issues of political correctness (e.g. disinvitation, role/aim of university, etc.) in American universities. In fact, the means $(\mu)$ vary astonishingly little $(\mathrm{MD}=0.48, \mathrm{SDD}=0.2767)$ and only twice do the SPCAA means $(\mu)$ vary by more than one (>1.0, e.g. Q1: 1.1, Q9: 1.1) point of general agreement/disagreement (for general picture, defer to Figure 2).

\section{Conclusions}

The homogeneity present in the responses seems to indicate that, in high schoolers, divergent political identities correlate poorly with differences of opinion surrounding the use and promulgation of PC culture in our university system. And preliminarily, that consensus seems to indict, not endorse, political correctness in the academy. Undoubtedly, a great range of opinion exists at different institutions and some are known for their respective tendencies (Stiksma 2020); however, as a matter of generality: censorship, overt and aggressive speech policing seems to be unattractive to this student sample. Moreover, MF theory was validated to the extent that highest scoring (e.g. most obviously) Liberals were the ones who dissented in favor of a stricter PC paradigm (top 19 scorers accounted for $70 \%$ of $n=27)$. Likewise, all $(100 \%$ of $n=4)$ of the Conservatives scored higher than average on the Sanctity/Purity axis revealing an elevated sensitivity to allied domains to the politically correct (though PC is most strongly grounded in Care/Harm). Ultimately, these data hint strongly at a consensus and may be indicative of a potentially up-coming change of the guard. The average teen appears not to feel censorship to be either valid or effective, at least in theory. Needless to say, who we are on paper does not necessarily translate into who we are in a group or collective-res, non verba. While MFT identifies who we are alone, tribal psychology, emotions, and Groupthink govern our actions in the heat of the moment and during moments of great consequence. 


\section{Lara Midkiff}

Figure 1. -Comparison of Political Identity: Self-Reported v. MFQ-Determined

50

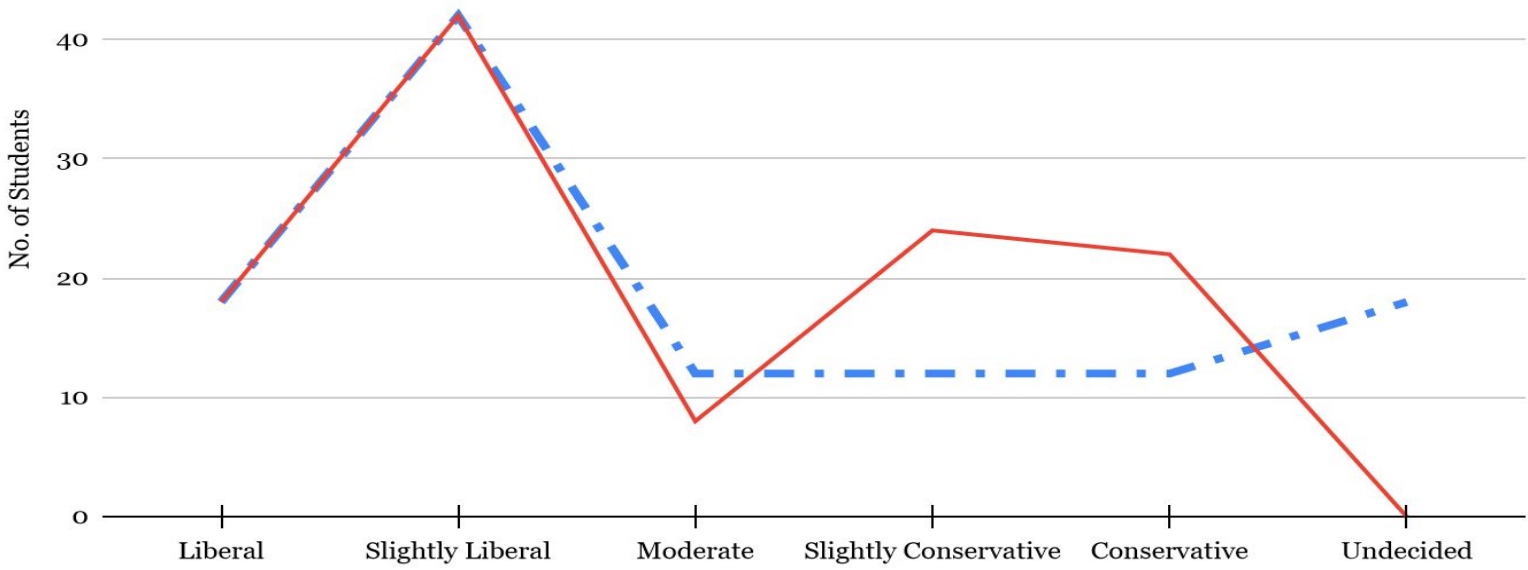

- = Dotted Blue-Self-Reported Political Identity $=$ Red-MFQ-Determined Political Identity

Figure 2.- $\mu$ SPCAA Values to Moral Foundations Identity

Mean $(\mu)$ SPCAA Value

Question/Prompt Items

Liberals $(\mathrm{n}=65) \quad$ Conservatives $(\mathrm{n}=49)$

1. There are certain topics too controversial and/or too indecent to be discussed in the 1.3 classrooms of colleges or universities.

2. In early 2017, the University of California, Berkeley, canceled a speaking engagement of Milo Yiannopoulos on campus on the grounds that Yiannopoulos was a 'divisive right-wing writer' who 'would inspire protest.' This was the correct and most prudent course of action for the University to take.

3. The top priority of the university is to ensure the emotional well-being of its student body.

4. Universities should revoke the tenures of professors who, in any capacity, directly or indirectly, discuss differences among races and/or the sexes in a classroom or laboratory setting.

5. Universities and their faculty should follow the truth, no matter where it leads.

6. Academic rigor should be the litmus test for universities, faculty, and course content, not personal opinion.

7. A student is personally offended by the content presented to them in a lecture. When they complain to the administration, the university moves to redirect the content of the course. This is the appropriate course of action by the university.

8. In a university setting, if a student and faculty member have a difference of opinion regarding content, weighing the evidence and having a thorough discussion is the best manner by which to resolve that difference.

9. Universities should operate out of respect to authority and seniority.

10. Activism and truth-seeking, within the context of the university, can never be contradictory endeavors. 


\section{References}

1. Graham, J., Haidt, J., Koleva, S., Motyl, M., Iyer, R., Wojcik, S. P., \& Ditto, P. H. (2012). Moral Foundations Theory: the pragmatic validity of moral pluralism. Advances in Experimental Social Psychology, 47, 55-130.

2. Haidt, J. (2012). The righteous mind: why good people are divided by politics and religion. New York: Vintage Books.

3. Gladden, PR \& Cleator, AM. (2018). Slow life history strategy predicts six moral foundations. The Journal of Evolutionary Studies Consortium, SEEPS II, 43-63.

4. Egorov, M., Kalshoven, K., Pircher Verdorfer, A., \& Peus, C. (2019). It's a Match: Moralization and the Effects of Moral Foundations Congruence on Ethical and Unethical Leadership Perception. Journal of Business Ethics, doi.org/10.1007/s10551-019-04178-9

5. Curry, O.S., Chesters, M.J., \& Van Lissa, C.J. (2019). Mapping morality with a compass: Testing the theory of 'morality-as-cooperation' with a new questionnaire. Journal of Research in Personality, 78(x), 106-124.

6. Harper, C. A., \& Harris, A. J. (2016). Applying moral foundations theory to understanding public views of sexual offending. Journal of Sexual Aggression, 1-13.

7. Bernstein, B. (1990). The Rising Hegemony of the Politically Correct. The New York Times.

8. Cohen, N. (2012). You can't read this book. London: Fourth Estate.

9. Ravitch, D. (2003). The language police: how pressure groups restrict what students learn. New York: Alfred A. Knopf.

10. Chemerinsky \& Gillman. (2017). Free Speech on Campus. New Haven: Yale University Press.

11. Graham, J., Haidt, J., \& Nosek, B. A. (2009). Liberals and conservatives rely on different sets of moral foundations. Journal of Personality and Social Psychology, 96(5), 1029-10 46.

12. Graham, J., Nosek, B., Haidt, J., Iyer, R., Koleva, S., Ditto, P.H. (2009). Mapping the moral domain. Journal of Personality and Social Psychology, 101, 366-385.

13. Trends in party affiliation among demographic groups. (2018). Pew Research Center: U.S. Politics \& Policy. Retrievable from https://www.pewresearch.org/politics/2018/03/20/1-tren ds-in-party-affiliation-among-demographic-groups/

14. Parker, K., Graf, N., Igielnik, R. Generation Z Looks a Lot Like Millennials on Key Social and Political Issues. (2019). Pew Research Center: Social and Demographic Trends. Retrievable from https://www.pewsocialtrends.org/2019/01/17/generation-z-looks-a-lot-like -millennials-on-key-social-and-political-issues/

15. Stiksma, M. (2020). Understanding the Campus Expression Climate: Fall 2019. Heterodox Academy. 


\section{Appendix A-Moral Foundations Questionnaire (MFQ)}

Part A. When you decide whether something is right or wrong, to what extent are the following considerations relevant to your thinking? Please rate each statement using this scale:

[0] = not at all relevant (This consideration has nothing to do with my judgments of right and wrong)

[1] $=$ not very relevant

[2] = slightly relevant

[3] = somewhat relevant

[4] = very relevant

[5] = extremely relevant (This is one of the most important factors when I judge right and wrong)

Whether or not someone suffered emotionally

Whether or not some people were treated differently than others

Whether or not someone's action showed love for his or her country

Whether or not someone showed a lack of respect for authority

Whether or not someone violated standards of purity and decency

Whether or not someone was good at math

Whether or not someone cared for someone weak or vulnerable

Whether or not someone acted unfairly

Whether or not someone did something to betray his or her group

Whether or not someone conformed to the traditions of society

Whether or not someone did something disgusting

Whether or not someone was cruel

Whether or not someone was denied his or her rights

Whether or not someone showed a lack of loyalty

Whether or not an action caused chaos or disorder

Whether or not someone acted in a way that God would approve of 
Part B. Please read the following sentences and indicate your agreement or disagreement:

$$
[\mathbf{0}]=\text { Strongly Disagree } \quad[\mathbf{1}]=\text { Moderately Disagree } \quad[2]=\text { Disagree } \quad[3]=\text { Agree }
$$

$$
[4]=\text { Moderately agree } \quad[5]=\text { Strongly agree }
$$

Compassion for those who are suffering is the most crucial virtue.

When the government makes laws, the number one principle should be ensuring that everyone is treated fairly.

I am proud of my country's history.

Respect for authority is something all children need to learn.

People should not do things that are disgusting, even if no one is harmed.

It is better to do good than to do bad.

One of the worst things a person could do is hurt a defenseless animal.

Justice is the most important requirement for a society.

People should be loyal to their family members, even when they have done something wrong.

Men and women each have different roles to play in society.

I would call some acts wrong on the grounds that they are unnatural.

It can never be right to kill a human being.

I think it's morally wrong that rich children inherit a lot of money while poor children inherit nothing.

It is more important to be a team player than to express oneself.

If I were a soldier and disagreed with my commanding officer's orders, I would obey anyway because that is my duty.

Chastity is an important and valuable virtue. 


\section{Appendix B-Student Political Correctness Attitude Assessment (SPCAA)}

\section{Please read the following sentences and indicate your agreement or disagreement:}

$$
\begin{aligned}
& {[\mathbf{0}]=\text { Strongly Disagree } \quad[\mathbf{1}]=\text { Moderately Disagree } \quad[\mathbf{2}]=\text { Slightly Disagree }} \\
& {[3]=\text { Slightly Agree } \quad[4]=\text { Moderately Agree } \quad[5]=\text { Strongly agree }}
\end{aligned}
$$

There are certain topics too controversial and/or too indecent to be discussed in the classrooms of colleges or universities.

In early 2017, the University of California, Berkeley, canceled a speaking engagement of Milo Yiannopoulos on campus on the grounds that Yiannopoulos was a 'divisive right-wing writer' who 'would inspire protest.' This was the correct and most prudent course of action for the University to take.

The top priority of the university is to ensure the emotional well-being of its student body.

Universities should revoke the tenures of professors who, in any capacity, directly or indirectly, discuss differences among races and/or the sexes in a classroom or laboratory setting.

Universities and their faculty should follow the truth, no matter where it leads.

Academic rigor should be the litmus test for universities, faculty, and course content, not personal opinion.

A student is personally offended by the content presented to them in a lecture. When they complain to the administration, the university moves to redirect the content of the course. This is the appropriate course of action by the university.

In a university setting, if a student and faculty member have a difference of opinion regarding content, weighing the evidence and having a thorough discussion is the best manner by which to resolve that difference.

Universities should operate out of respect to authority and seniority.

Activism and truth-seeking, within the context of the university, can never be contradictory endeavors.

\section{Appendix C-SPCAA Scoring Guidelines}

